Journal of Chromatography A

Archimer

December 2014, Volume 1373, Pages 1-8

http://dx.doi.org/10.1016/j.chroma.2014.11.008

http://archimer.ifremer.fr/doc/00226/33766/

(C) 2014 Elsevier B.V. All rights reserved.

\title{
Effect of seawater salinity on pore-size distribution on a poly(styrene)-based resin and its adsorption of diarrhetic shellfish toxins
}

\author{
Fan Lin ${ }^{1}$, Sun Geng ${ }^{1}$, Qiu Jiangbing ${ }^{1}$, Ma Qimin ${ }^{1,2}$, Hess Philipp ${ }^{3}$, Li Aifeng ${ }^{1,2, ~ *}$
}

\author{
${ }^{1}$ College of Environmental Science and Engineering, Ocean University of China, Qingdao 266100, China \\ ${ }^{2}$ Key Laboratory of Marine Environment and Ecology, Ocean University of China, Ministry of Education, \\ Qingdao 266100, China \\ ${ }^{3}$ Ifremer, Laboratoire Phycotoxines, 44311 Nantes, France \\ * Corresponding author : Aifeng Li, tel.: +86 53266781935 ; email address : lafouc@ouc.edu.cn
}

\begin{abstract}
:
In the present study, okadaic acid (OA) and dinophysistoxin-1 (DTX1) were spiked into artificial seawater at low, medium and high estuarine salinities (9\%, 13.5\% and 27\%o). Passive samplers (HP20 resin) used for solid phase adsorption toxin tracking (SPATT) technology were exposed in these seawaters for $12-h$ periods. Adsorption curves well fitted a pseudo-secondary kinetics model. The highest initial sorption rates of both toxins occurred in the seawater of medium salinity, followed by seawater of low and high estuarine salinity. Pore volumes of micropores $(<2 \mathrm{~nm})$ and small mesopores $(2 \mathrm{~nm}<$ diameter $<10 \mathrm{~nm}$ ) of HP20 resin decreased after adsorption of toxins in seawater at high and low salinity but not in seawater at medium salinity, which demonstrated that the toxin molecules entered into micropores and mesopores (below $10 \mathrm{~m}$ in size) in seawaters of high and low salinity. More toxin or other matrix agglomerates were displayed on the surface of resin deployed in the seawater of medium salinity. Taking into consideration the pore-size distribution and surface images, it appears that intraparticle diffusion governs toxin adsorption in seawater at high salinity while film diffusion mainly controls the adsorption process in seawater at medium salinity. This is the first study to confirm that molecules of OA and DTX1 are able to enter into micropores $(<2 \mathrm{~nm})$ and small mesopores $(2-10 \mathrm{~nm})$ of HP20 resin in estuarine seawater with high salinity $(\sim 27 \%)$.
\end{abstract}

\section{Highlights}

- HP20 resin bags were deployed in three artificial seawaters at different salinity. Dynamic adsorption behaviour of OA and DTX1 by these SPATT bags was explored. The highest initial sorption rate of toxins occurred in seawater at medium salinity. Resin pores below $10 \mathrm{~nm}$ in size governed adsorption in natural seawater. Toxins were retained by pores in seawaters at high and low salinity.

Keywords : Diarrhetic shellfish toxins (DST), Solid phase adsorption toxin tracking (SPATT), HP20 resin, Salinity, Pore-size distribution, Pseudo-secondary kinetics equation 


\section{Introduction}

Micro-algal toxins potentially threaten mariculture industry and ecosystem health as toxic algal blooms occur frequently and globally in coastal waters [1,2]. Based on their chemical structures, these micro-algal toxins are classified into total eight groups including the okadaic acid (OA), azaspiracid (AZA), yessotoxin (YTX), pectenotoxin (PTX), brevetoxin, cyclic imine, saxitoxin (STX), and domoic acid (DA) groups.

They can be accumulated and transferred along food webs of marine ecosystems including cultivated shellfish [3-5]. Therefore, poisoning events and victims frequently occurred due to consumption of contaminated seafood [6-8]. For example, diarrhetic shellfish poisoning (DSP) as a familiar poisoning event is related to OA-group toxins, including OA and its derivatives dinophysistoxin-1 (DTX1) and epimer DTX2, accumulated by crabs, mussels, etc [9-12]. Although no victims were recorded by DSP events, a link was hypothesized between exposure to OA-group toxins and tumor enhancement [13-14]. Thus, it is very important to monitor and forecast the pollution of micro-algal toxins in mariculture zones in order to protect seafood safety and consumer health.

A technology referred to as Solid Phase Adsorption Toxin Tracking (SPATT) was developed to monitor the occurrence of toxic algal blooms and shellfish contamination events in seawater using porous synthetic resin [15]. Various micro-algal toxins were tentatively monitored using the SPATT method for adsorption in the laboratory or in the field [16-20]. The SPATT technology has been shown to provide reliable, sensitive, time-integrated sampling of various micro-algal toxins to 
monitor the occurrence of toxic algal bloom events [21]. Comparative results for several different adsorbents showed that the resin DIAION ${ }^{\circledR} \mathrm{HP} 20$ has greater adsorption quantity and higher desorption rate of lipophilic toxins $[15,16]$. The key role played by the pore-size distribution, especially micropores of resin, for OA-group toxins was hypothesized in our previous study [22]. Utility of SPATT bags packaged by HP20 resin was also demonstrated to successfully monitor microcystins in freshwater [23]. Presently, the range of sorbents for passive sampling of micro-algal toxins was extended and assessed in laboratory and field studies [24]. However, the relationship between the quantity obtained by SPATT bags and toxin content accumulated by shellfish has still not been successfully modelled until now, although some efforts into this direction have been made [25]. Also, knowledge on the adsorption mechanism of toxins by resins and the effect of salinity on the adsorption process is still limited. In the present study, the dynamic adsorption of OA and DTX1 toxins by HP20 resin in artificial seawater at different salinity was simulated in laboratory. The pore-size distribution and surface image of resins before and after adsorption toxins were explored to discuss the effect of salt matrix on the dynamic adsorption of toxins by HP20 resin.

\section{Materials and methods}

\subsection{Chemicals}

All reagents and solvents used in the study were HPLC grade. Acetonitrile and methanol were purchased from Merck Ltd. (Whitehouse Station, NJ, USA). Formic acid (FA) and ammonium formate (AF) were purchased from Fisher Scientific (Fair 
Lawn, NJ, USA). Standard OA and DTX1 were purchased from the Certified

Reference Materials Program (CRMP) of the National Research Council of Canada

(Halifax, NS, Canada) and Wako Pure Chemical Industries, Ltd. (Osaka, Japan), respectively. Pure water was obtained from a MilliQ water purification system (Millipore Ltd., Bedford, MA, USA) to $18.2 \mathrm{M} \Omega \mathrm{cm}^{-1}$ quality or better.

\subsection{Adsorbent resin}

DIAION ${ }^{\circledR}$ HP20 was purchased From the Mitsubishi Chemical Corporation (Tokyo, Japan). It is an aromatic type adsorbent based on a cross-linked polystyrene matrix. The manufacturer stated that particles of HP20 resin are $250-600 \mu \mathrm{m}$ (more than $90 \%$ particles $>250 \mu \mathrm{m})$.

\subsection{Dynamic adsorption of $O A$ and DTX1 by HP2O resin in artificial seawaters}

SPATT bags were made of polyester mesh, $40 \mathrm{~mm} \times 40 \mathrm{~mm}$, and were packed with $3.0 \mathrm{~g}$ of dry HP20 resin. They were immersed in methanol for $48 \mathrm{~h}$ to activate the HP20 resin. Then they were washed three times using bulk Milli-Q water before storage in pure water for use.

According to the manufacturer's statement, $31 \mathrm{~g}$ sea salt was dissolved in $1 \mathrm{~L}$ of pure water to simulate nature seawater with the content of $\mathrm{NaCl}, \mathrm{MgSO}_{4} \cdot 7 \mathrm{H}_{2} \mathrm{O}$, $\mathrm{MgCl}_{2} \cdot 6 \mathrm{H}_{2} \mathrm{O}, \mathrm{CaCl}_{2} \cdot \mathrm{H}_{2} \mathrm{O}$ and $\mathrm{KCl}$ at $65.0 \pm 5.0,15.0 \pm 2.0,12.0 \pm 2.0,4.0 \pm 1.0$, and $1.5 \pm 1.4$, respectively. In this study, $31 \mathrm{~g}, 15.5 \mathrm{~g}$ and $10.3 \mathrm{~g}$ sea salt were dissolved in $1 \mathrm{~L}$ of pure water to make the artificial seawater at high, medium, and low salinity, respectively. Salinity of the artificial seawater at high salinity was approximately $27 \%$, which was lower than that of normal natural seawater. Purified extracts of OA and 
110

111

112

113

114

115

116

117

118

119

120

121

122

123

124

125

126

127

128

129

130

131

DTX1 toxins $(10 \mathrm{~mL})$ through solid-phase extraction (SPE) were dissolved in

different salinity matrix and were added into the corresponding artificial seawater.

The initial concentrations of OA and DTX1 toxins in the adsorption system were 2.70

and $3.92 \mathrm{ng} / \mathrm{mL}$, respectively. Three SPATT bags of HP20 resin were separately put

into the different artificial seawater strengths using a weight to hold them in the

middle of the container. The adsorption system was stirred continuously at $145 \mathrm{rpm}$

by a magnetic stirring apparatus at $25 \pm 1^{\circ} \mathrm{C}$ in order to make toxins well-distributed.

Sampling time point was set at 0, 10, 20, 30, 45, 60, 90, 120, 240, 480 and 720

min. Triplicate of $1.5 \mathrm{~mL}$ seawater was taken from the adsorption system at every

sampling time point, respectively. These samples were purified by the Oasis ${ }^{\circledR} \mathrm{HLB}$

SPE cartridge (3cc, 60mg). $2 \mathrm{~mL}$ of methanol and $2 \mathrm{~mL}$ of water was successively

used to activate and equilibrate the cartridges, respectively, before loading $1.5 \mathrm{~mL}$ of

samples. Aliquots ( $2 \mathrm{~mL}$ ) of $5 \%$ methanol (methanol/water, 5/95, v/v) were used to

wash and methanol ( $2 \mathrm{~mL})$ was used to elute toxins. Finally, the eluate was dried by

nitrogen gas and reconstituted in $1.5 \mathrm{~mL}$ of methanol. Then, the samples were filtered by $0.22 \mu \mathrm{m}$ organic membrane and analyzed using LC-MS/MS. Meanwhile, the same

SPATT bags were deployed in different artificial seawater without micro-algal toxins

in a $1 \mathrm{~L}$ flask as blank control experiment.

\subsection{LC-MS/MS analysis for OA and DTX1}

An Agilent 6430 tandem quadrupole mass spectrometer equipped with an Agilent 1290 HPLC (Palo Alta, CA, USA) using an ESI interface was used to analyze all samples here. Chromatographic separation was achieved on a $50 \times 2.1 \mathrm{~mm}$ i.d., 
132

$3 \mu \mathrm{m}$, Luna C18 column (Phenomenex) maintained at $35^{\circ} \mathrm{C}$. The mobile phase

gradient was composed by solvent A (water) and solvent B (95\% acetonitrile), each

containing $50 \mathrm{mM}$ formic acid and $2 \mathrm{mM}$ ammonium formate. A gradient was run

from $25 \%$ to $100 \% \mathrm{~B}$ over $7 \mathrm{~min}$, holding for $3 \mathrm{~min}$ and back to $25 \% \mathrm{~B}$ to

re-equilibration for $2 \mathrm{~min}$ for the next run. Flow rate was set at $300 \mu \mathrm{L} / \mathrm{min}$ and the

injection volume was $5 \mu \mathrm{L}$. MS detection was carried out with positive ionization

mode. Multiple reaction monitoring (MRM) acquisition mode was used for qualitative and quantitative analysis for OA (m/z 827.5 -> 809.4 / 791.3 / 723.4) and DTX1 (m/z 841.5 -> 823.5 / 805.5 / 737.4).

\subsection{Measure for surface area and porosity of resin}

HP20 resin was taken out from the SPATT bag after exposure in the adsorption experiments. The resin was freeze-dried using a lyophilizer at $-40^{\circ} \mathrm{C}$. Pore volume and pore-size distribution were determined by a gas sorption system (Micrometrics, ASAP $^{\circledR} 2020$, USA) using nitrogen as adsorbate. About $100 \mathrm{mg}$ of resin was degassed at $105^{\circ} \mathrm{C}$ until the pressure increase rate was lower than $1.3 \mathrm{~Pa} / \mathrm{min}$ within a 0.5 -min test interval. Helium was used as a backfill gas. In total, 106 adsorption points and 54 desorption points were collected from $5.63 \times 10^{-7}$ to $0.995 \mathrm{P} / \mathrm{P} 0$.

\subsection{Scanning electron microscopy for HP2O resin}

The surface texture of HP20 resin in different artificial seawater spiked with or without OA and DTX1 toxins were characterized by a scanning electron microscope (SEM) (Hitachi, S-4800, Japan). All resin samples were freeze-dried under vacuum and then were fixed on aluminum stubs and coated with gold before observation using 
154

155

157

158

159

160

161

162

163

164

165

SEM.

\section{Results and Discussion}

3.1. Dynamic adsorption behavior of OA and DTX1 toxins by HP2O resin in different artificial seawater

Chemical structures of OA and DTX1 toxins are shown in Fig. 1. These

polyether toxins can be dissolved in seawater due to salt matrix but not in freshwater because of their hydrophobic property. It is very difficult to arrange duplicate SPATT bags for each sampling time point because of limits of toxins and experimental space.

The dynamic adsorption quantity of toxins on SPATT bags was calculated by the concentration discrepancy between two adjacent samplings from seawater. The chromatograms of OA and DTX1 toxins acquired by different transitions using LC-MS/MS are shown in Fig. 2. Retention times of OA and DTX1 toxins were 5.0 and $6.0 \mathrm{~min}$, respectively, under these chromatographic conditions. The chromatograms demonstrated that no obvious matrix interferences were found due to potential remaining salt matrix in the seawater samples purified by SPE cartridges. Limits of quantification (LOQ, signal / noise $=10$ ) of the LC-MS/MS method for standard OA and DTX1 were measured as 0.23 and $0.07 \mathrm{ng} / \mathrm{mL}$ (injection volume 5 $\mu \mathrm{L})$, respectively, using the $\mathrm{S} / \mathrm{N}$ values of the lowest transitions of OA (827.5 -> 791.3) and DTX1 (841.5 -> 805.5). Dynamic adsorption curves of OA and DTX1 toxins adsorbed by HP20 resin in different artificial seawater are shown in Fig. 3. The curves showed that OA and DTX1 toxins could be adsorbed fast by HP20 resin in three different artificial 
176

177

178

179

180

181

182

183

184

185

186

187

seawaters. The adsorption curves were close to linear type in the first 90-min time

period. Relatively, the adsorption rates of OA and DTX1 toxins were the slowest in seawater at high salinity over the first 120 -min; then they exceeded those in the seawater of low salinity after this period. Totally the adsorption rates of toxins in the seawater of medium salinity were the fastest in whole exposure period and there were no detectable toxins in this seawater after 480-min adsorption. The adsorption curves were simulated by five different dynamic adsorption models including the Elovich equation, double constant equation, parabolic diffusion equation, first-order kinetics equation and pseudo-secondary kinetics equation. The determination coefficient $\left(R^{2}\right)$ demonstrated that the dynamic adsorption curves could be well fitted by the pseudo-secondary kinetics equation (Table 1 ). Values of $R^{2}$ fitted by the pseudo-secondary kinetics equation decreased with the salinity in three different artificial seawaters, which demonstrated that the salinity of seawater slightly reduced the fit quality of the model.

Initial sorption rate $h(\mathrm{ng} /(\mathrm{g} \cdot \mathrm{min}))$ and equilibrium sorption quantity $\mathrm{Q}_{\mathrm{e}}(\mathrm{ng} / \mathrm{g})$ could be calculated using the pseudo-secondary kinetics equation using $h=1 / \mathrm{a}$ and $\mathrm{Q}_{\mathrm{e}}=1 / \mathrm{b}[26]$. The highest initial sorption rate occurred in the artificial seawater at medium salinity, followed by the treatment with low and high salinity (Table 2). This discrepancy showed that the salt matrix effectively reduced the initial sorption rates of OA and DTX1 toxins by HP20 resin. The initial sorption rate of OA was also less than that of DTX1 in three different artificial seawaters, which had been reported and explained by the extra methyl group of DTX1 in our previous study [22]. Average 
198

199

linear sorption rates of OA and DTX1 toxins by HP20 resin were also directly calculated using the adsorption quantity divided by time period (Fig. 4). Average adsorption rates of OA and DTX1 in the seawater of low salinity slightly exceeded that in seawater of medium salinity in the early 10 -min period. After this period the average adsorption rates in artificial seawater of medium salinity were the fastest, followed by the treatments of low and high salinity. This discrepancy of average linear adsorption rates also demonstrated that the salinity of seawater affected the dynamic adsorption behavior of lipophilic toxins by HP20 resin. Meanwhile, the average adsorption rates of OA in different seawater salinities were lower than those of DTX1 due to the difference of chemical structure. However, the equilibrium sorption quantities of OA and DTX1 toxins calculated by the pseudo-secondary kinetics equation increased with the salinity in three different artificial seawaters although the experimental sorption quantities were similar in all treatments (Table 2). The concentrations of OA $(2.70 \mathrm{ng} / \mathrm{mL})$ and DTX1 $(3.92 \mathrm{ng} / \mathrm{mL})$ used in this study were several hundreds of times higher than the dissolved OA concentration ranging from 4.24 to $9.64 \mathrm{ng} / \mathrm{L}$ in coastal seawater of Qingdao City, China [27]. Theoretically the experimental quantities of OA and DTX1 were 900 and $1307 \mathrm{ng} / \mathrm{g}$ resin, respectively, if the toxins spiked into seawater were completely adsorbed by resin in the whole experimental period. The adsorption percentage of OA and DTX1 spiked into three different seawaters was over $96 \%$ and $98 \%$, respectively, when the adsorption experiment was finished in the study. These high percentages demonstrated that OA and DTX1 toxins were almost completely adsorbed by SPATT bags in the 
220

221

222

223

224

225

226

227

228

229

230

231

232

233

234

235

236

237

238

239

240

241

experimental period. Therefore, the calculated equilibrium sorption quantities of OA

and DTX1 in the artificial seawater increased with salinity because the salinity

reduced the fit of the equation for adsorption. This point has been demonstrated by the

values of determination coefficient $R^{2}$. Totally, the dynamic adsorption process could

be well fitted by the pseudo-secondary kinetics equation which suggests that either

film diffusion or intra-particle diffusion controls the overall rate of adsorption [26].

Usually the dynamic adsorption process simultaneously depends on the large specific

surface area and small size pores in the adsorbent. It means that the film diffusion

governs adsorption process if the specific surface area plays dominant role; reversely

it means the intra-particle diffusion governs the adsorption process. The intra-particle

diffusion was hypothesized to govern the capacity and equilibration rate of toxin

adsorption by HP20 resin in seawater of micro-algal cultures [16]. The important

roles caused by micropores $(<2 \mathrm{~nm})$ of HP20 resin in $90 \%$ methanol solution were

also suggested in our previous study [22]. The dynamic adsorption behaviors of OA

and DTX1 toxins by HP20 resin in different seawaters also comply with this rule in this study.

\subsection{Change of pore-size distribution of HP2O resin after adsorption for toxins}

In order to explore the mechanism by which salt affects the dynamic adsorption

of toxins by resin, the pore-size distribution of HP20 resin deployed in seawater with or without OA/DTX1 toxins was characterized. Results showed that no obvious

change of the pore volumes of size between 10-20 nm was found in HP20 resin

deployed in three different seawaters with or without toxins (Fig. 5). However, the 
pore volumes of micropores (diameter $<2 \mathrm{~nm}$ ) and small mesopores $(2 \mathrm{~nm}<$ diameter

$<10 \mathrm{~nm}$ ) decreased after toxins were adsorbed onto HP20 resin in the artificial

seawaters at high salinity and low salinity, which demonstrated that toxin molecules

entered into these small size pores. Inconsistently, the pore volumes of micropores did not change whether the resin adsorbed toxins or not, and the pore volumes of small mesopores (2 - $10 \mathrm{~nm}$ ) also did not change obviously and consistently in the artificial seawater at medium salinity. This phenomenon testified that the toxin molecules did not enter into the micropores and small mesopores $(2-10 \mathrm{~nm})$ in the seawater of medium salinity. Interestingly, the pore volumes of micropores or mesopores (2 - 10 $\mathrm{nm}$ ) of HP20 resin deployed in the artificial seawater of high salinity without toxins were higher than those in the artificial seawater of low salinity without toxins, which showed that solely the salt matrix of seawater also changed the pore size distribution of resin. Possibly, salt matrix would reconstruct these pores in some big pores of HP20 resin. The largest BET surface area of HP20 resin before adsorption toxins occurred in the seawater at high salinity, followed by the treatments of low and medium salinity (Table 3), which demonstrated that the salt matrix changed the surface area of resin. Consistently, the surface areas of resins decreased after they adsorbed toxins in three different seawaters. However, the average pore volume of resin deployed in the seawater at medium salinity increased after it adsorbed toxins, which also demonstrated that toxin molecules did not enter into these pores of resin. Therefore, the HP20 resin deployed in the seawater at medium salinity displayed the highest initial sorption rate because only film diffusion governed the adsorption 
264

265

266

267

268

269

270

271

272

273

274

275

276

277

278

279

280

281

282

283

284

285

process.

In order to testify the discrepancy of adsorption behavior in different seawaters, the surface images of resin deployed in artificial seawaters were characterized by

SEM. Results showed that the surface of resins deployed in three different seawaters without toxins were very clean (Fig. 6), which demonstrated that the salt matrix did not change resin surface. Some agglomerates emerged on the surface of resins exposed to algal extracts in seawaters of medium and low salinity, but not on the surface of resin adsorbed toxins in the seawater of high salinity (Fig. 6). More agglomerates occurred on the surface of resin deployed in the seawater at medium salinity comparatively to the seawater at low salinity. To our knowledge we could not explain the occurrence of agglomerates on the surface of resin deployed in the low salinity seawater. However, the SEM results testified that the toxins were mainly adsorbed onto the surface of resin deployed in the seawater at medium salinity $(\sim 13.5 \%$ ) , which could explain the highest initial sorption rate due to the film diffusion related with surface adsorption.

Based on the findings of this study, it could be safely concluded that the intra-particle diffusion governs the adsorption process of HP20 resin for toxins in estuarine seawater with high salinity while film diffusion controls the adsorption process in seawater at medium salinity $(\sim 13.5 \%)$. Also, the adsorption process of HP20 resin for toxins is dependent on both film diffusion and intra-particle diffusion in seawater of low salinity ( 9\%o). The different adsorption mechanisms for HP20 resin in seawaters with different salinity suggest that the adsorption behavior of toxins 
286

287

288

289

290

291

292

293

294

295

296

297

298

299

300

301

302

303

304

305

306

307

by SPATT deployments in estuaries with low salinity should be different to those in natural seawater.

\section{Conclusions}

In this study, purified extract containing OA and DTX1 toxins from

Prorocentrum lima was spiked into three artificial seawaters at different salinity (27\%o, 13.5\% and 9\%o) and SPATT samplers of HP20 resin were deployed in these seawaters for 720-min exposure. Adsorption curves of toxins in seawater of three different salinities well fitted the pseudo-secondary kinetics equation. However, the pore-size distribution and specific surface area of HP20 resins deployed in seawater with or without toxins were affected and not linearly related to the salinity of seawater. According to the findings of this study, it is confirmed that the molecules of OA and DTX1 are able to enter into the micropores and small mesopores (2 - $10 \mathrm{~nm}$ ) of HP20 resin in estuarine seawater at high salinity $(\sim 27 \%$ ). The intra-particle diffusion governs the adsorption process of HP20 resin for toxins in seawater with high salinity $(\sim 27 \%$ ) , while film diffusion controls the adsorption process in seawater at medium salinity $(\sim 13.5 \%$ ) . Further studies should clarify whether the effect of salinity on adsorption kinetics is sufficiently significant at the naturally low concentrations of toxins in seawater to play a role during daily or weekly monitoring.

\section{Supplementary materials}

Extraction and purification methods for OA and DTX1 toxins could be found in the supplementary file.

\section{Acknowledgement}


309 and Quarantine, People's Republic of China (201310141), and the National Natural

310 Science Foundation of China (41276103).

311 Conflict of interest statement

312 All authors declare that there are no conflicts of interest. 
313

314

315

316

317

318

319

320

321

322

323

324

325

326

327

328

329

330

331

332

333

334

\section{References}

[1] L. Botes, A.J. Smit, P.A. Cook, The potential threat of algal blooms to the abalone (Haliotis midae) mariculture industry situated around the South African coast, Harmful Algae 2 (2003) 247-259.

[2] T.G. Park, W.A. Lim, Y.T. Park, C.K. Lee, H.J. Jeong, Economic impact, management and mitigation of red tides in Korea, Harmful Algae 30S1 (2013) S131-S143.

[3] L.F. Leandro, G.J. Teegarden, P.B. Roth, Z. Wang, G.J. Doucette, The copepod Calanus finmarchicus: A potential vector for trophic transfer of the marine algal biotoxin, domoic acid, J. Exp. Mar. Biol. Ecol. 382 (2010) 88-95.

[4] R.W.M. Kwong, W.-X. Wang, P.K.S. Lam, P.K.N. Yu, The uptake, distribution and elimination of paralytic shellfish toxins in mussels and fish exposed to toxic dinoflagellates, Aquat. Toxicol. 80 (2006) 82-91.

[5] V.M. Lopes, M. Baptista, T. Repolho, R. Rosa, P.R. Costa, Uptake, transfer and elimination kinetics of paralytic shellfish toxins in common octopus (Octopus vulgaris), Aquat. Toxicol. 146 (2014) 205-211.

[6] A.P. Sierra-Beltrán, A. Cruz, E. Núñez, L.M. Del Villar, J. Cerecero, J.L. Ochoa, An overview of the marine food poisoning in Mexico, Toxicon 36 (1998) 1493-1502.

[7] A. Furey, S. O'Doherty, K. O'Callaghan, M. Lehane, K.J. James, Azaspiracid poisoning (AZP) toxins in shellfish: Toxicological and health considerations, Toxicon 56 (2010) 173-190. 
335

336

337

338

339

340

341

342

343

344

345

346

347

348

349

350

351

352

353

354

355

356

[8] L.E. Fleming, B. Kirkpatrick, L.C. Backer, C.J. Walsh, K. Nierenberg, J. Clark, A. Reich, J. Hollenbeck, J. Benson, Y.S. Cheng, J. Naar, R. Pierce, A.J. Bourdelais, W.M. Abraham, G. Kirkpatrick, J. Zaias, A. Wanner, E. Mendes, S. Shalat, P. Hoagland, W. Stephan, J. Bean, S. Watkins, T. Clarke, M. Byrne, D.G. Baden, Review of Florida red tide and human health effects, Harmful Algae 10 (2011) 224-233.

[9] T. Torgersen, J. Aasen, T. Aune, Diarrhetic shellfish poisoning by okadaic acid esters from Brown crabs (Cancer pagurus) in Norway, Toxicon 46 (2005) 572-578.

[10] E. Prassopoulou, P. Katikou, D. Georgantelis, A. Kyritsakis, Detection of okadaic acid and related esters in mussels during diarrhetic shellfish poisoning (DSP) episodes in Greece using the mouse bioassay, the PP2A inhibition assay and HPLC with fluorimetric detection, Toxicon 53 (2009) 214-227.

[11] A. Li, J. Ma, J. Cao, P. McCarron, Toxins in mussels (Mytilus galloprovincialis) associated with diarrhetic shellfish poisoning episodes in China, Toxicon 60 (2012) 420-425.

[12] A. Li, G. Sun, J. Qiu, L. Fan, Lipophilic shellfish toxins in Dinophysis caudata picked cells and in shellfish from the East China Sea, Environ. Sci. Pollut. Res. xxx (2014) xxx. Doi: 10.1007/s11356-014-3595-z

[13] S. Cordier, C. Monfort, L. Miossec, S. Richardson, C. Belin, Ecological analysis of digestive cancer mortality related to contamination by diarrhetic shellfish poisoning toxins along the coasts of France, Environ. Res. 84 (2000) 145-150. 
357

358

359

360

361

362

363

364

365

366

367

368

369

370

371

372

373

374

375

376

377

378

[14] E. Manerio, V.L. Rodas, E. Costas, J.M. Hernandez, Shellfish consumption: A major risk factor for colorectal cancer, Med. Hypotheses 70 (2008) 409-412.

[15] L. MacKenzie, V. Beuzenberg, P. Holland, P. McNabb, A. Selwood, Solid phase adsorption toxin tracking (SPATT): a new monitoring tool that simulates the biotoxin contamination of filter feeding bivalves, Toxicon 44 (2004) 901-918.

[16] E. Fux, C. Marcaillou, F. Mondeguer, R. Bire, P. Hess, Field and mesocosm trials on passive sampling for the study of adsorption and desorption behaviour of lipophilic toxins with a focus on OA and DTX1, Harmful Algae 7 (2008) 574-583.

[17] E. Fux, R. Bire, P. Hess, Comparative accumulation and composition of lipophilic marine biotoxins in passive samplers and in mussels (M. edulis) on the West Coast of Ireland, Harmful Algae 8 (2009) 523-537.

[18] T. Rundberget, E. Gustad, I.A. Samdal, M. Sandvik, C.O. Miles, A convenient and cost-effective method for monitoring marine algal toxins with passive samplers, Toxicon 53 (2009) 543-550.

[19] P. Rodríguez, A. Alfonso, E. Turrell, J.-P.Lacaze, L.M. Botana, Study of solid phase adsorption of paralytic shellfish poisoning toxins (PSP) onto different resins, Harmful Algae 10 (2011) 447-455.

[20] A. Caillaud, P. de la Iglesia, E. Barber, H. Eixarch, N. Mohammad-Noor, T. Yasumoto, J. Diogène, Monitoring of dissolved ciguatoxin and maitotoxin using solid-phase adsorption toxin tracking devices: Application to Gambierdiscus pacificusin culture, Harmful Algae 10 (2011) 433-446. 
379 [21] L.A. MacKenzie, In situ passive solid-phase adsorption of micro-algal biotoxins as a monitoring tool, Curr. Opin. Biotech. 21 (2010) 326-331.

[22] A. Li, F. Ma, X. Song, R. Yu, Dynamic adsorption of diarrhetic shellfish poisoning (DSP) toxins in passive sampling relates to pore size distribution of aromatic adsorbent, J. Chromatogr. A 1218 (2011) 1437-1442.

[23] H. Zhao, J. Qiu, H. Fan, A. Li, Mechanism and application of solid phase adsorption toxin tracking for monitoring microcystins, J. Chromatogr. A 1300 (2013) 159-164.

[24] Z. Zendong, C. Herrenknecht, E. Abadie, C. Brissard, C. Tixier, F. Mondeguer, V. Séchet, Z. Amzil, P. Hess, Extended evaluation of polymeric and lipophilic diarrhetic shellfish poisoning in the coastal seawater of Qingdao City, China, 
403 Table1 Dynamic adsorption equations for OA and DTX1 toxins by HP20 resin simulated using different mathematical models.

\begin{tabular}{|c|c|c|c|c|c|c|}
\hline $\begin{array}{c}\text { Salinity of } \\
\text { seawater }\end{array}$ & Toxins & $\begin{array}{l}\text { Elovich equation } \\
q=\mathrm{a}+\mathrm{b} \times \operatorname{Ln} t\end{array}$ & $\begin{array}{l}\text { Double constant equation } \\
\operatorname{Ln} q=b \times \operatorname{Ln} t+\operatorname{Lna}\end{array}$ & $\begin{array}{l}\text { Parabolic diffusion equation } \\
q=\mathrm{a}+\mathrm{b} \times \sqrt{t}\end{array}$ & $\begin{array}{l}\text { First order kinetic } \\
\text { equation } \\
\text { Ln } q=\mathbf{a}+\mathbf{b} \times t\end{array}$ & $\begin{array}{l}\text { Pseudo-secondary } \\
\text { kinetics equation } \\
t / q=\mathrm{a}+\mathrm{b} \times t\end{array}$ \\
\hline High salinity & OA & $\begin{array}{l}\mathrm{y}=134.8 \mathrm{x}-306.1 \\
R^{2}=0.9199\end{array}$ & $\begin{array}{l}\mathrm{y}=0.558 \mathrm{x}+3.43 \\
R^{2}=0.9215\end{array}$ & $\begin{array}{l}\mathrm{y}=38.62 \mathrm{x}+31.46 \\
R^{2}=0.8993\end{array}$ & $\begin{array}{l}\mathrm{y}=0.0158 \mathrm{x}+4.16 \\
R^{2}=0.9588\end{array}$ & $\begin{array}{l}\mathrm{y}=0.00091 \mathrm{x}+0.1153 \\
R^{2}=0.9776\end{array}$ \\
\hline$(27 \% \circ)$ & DTX1 & $\begin{array}{l}\mathrm{y}=333.5 \mathrm{x}-790.1 \\
R^{2}=0.9502\end{array}$ & $\begin{array}{l}\mathrm{y}=0.684 \mathrm{x}+3.28 \\
R^{2}=0.9517\end{array}$ & $\begin{array}{l}\mathrm{y}=56.74 \mathrm{x}+40.54 \\
R^{2}=0.8923\end{array}$ & $\begin{array}{l}\mathrm{y}=0.0043 \mathrm{x}+5.61 \\
R^{2}=0.5324\end{array}$ & $\begin{array}{l}\mathrm{y}=0.00062 \mathrm{x}+0.0816 \\
R^{2}=0.9832\end{array}$ \\
\hline $\begin{array}{l}\text { Medium } \\
\text { salinity } \\
(13.5 \%)\end{array}$ & $\begin{array}{c}\text { OA } \\
\text { DTX1 }\end{array}$ & $\begin{array}{l}\mathrm{y}=116.2 \times-166.5 \\
R^{2}=0.9474 \\
\mathrm{y}=302.2 \times-488.3 \\
R^{2}=0.9597\end{array}$ & $\begin{array}{l}\mathrm{y}=0.449 \mathrm{x}+4.29 \\
R^{2}=0.9305 \\
\mathrm{y}=0.438 \mathrm{x}+4.70 \\
R^{2}=0.9371\end{array}$ & $\begin{array}{l}\mathrm{y}=44.51 \mathrm{x}+106.73 \\
R^{2}=0.8816 \\
\mathrm{y}=63.45 \mathrm{x}+153.12 \\
R^{2}=0.8858\end{array}$ & $\begin{array}{l}\mathrm{y}=0.0027 \mathrm{x}+5.84 \\
R^{2}=0.5225 \\
\mathrm{y}=0.0027 \mathrm{x}+6.20 \\
R^{2}=0.5452\end{array}$ & $\begin{array}{l}\mathrm{y}=0.00098 \mathrm{x}+0.0534 \\
R^{2}=0.9957 \\
\mathrm{y}=0.00069 \mathrm{x}+0.0374 \\
R^{2}=0.9951\end{array}$ \\
\hline $\begin{array}{c}\text { Low } \\
\text { salinity } \\
(9 \% \circ)\end{array}$ & DTX1 & $\begin{array}{l}\mathrm{y}=99.1 \mathrm{x}-125.0 \\
R^{2}=0.9573 \\
\mathrm{y}=263.1 \mathrm{x}-406.5 \\
R^{2}=0.9761\end{array}$ & $\begin{array}{l}\mathrm{y}=0.329 \mathrm{x}+4.20 \\
R^{2}=0.9476 \\
\mathrm{y}=0.383 \mathrm{x}+4.81 \\
R^{2}=0.9456\end{array}$ & $\begin{array}{l}\mathrm{y}=31.97 \mathrm{x}+139.03 \\
R^{2}=0.8995 \\
\mathrm{y}=48.06 \mathrm{x}+195.47 \\
R^{2}=0.8963\end{array}$ & $\begin{array}{l}\mathrm{y}=0.0083 \mathrm{x}+4.97 \\
R^{2}=0.9440 \\
\mathrm{y}=0.0027 \mathrm{x}+6.10 \\
R^{2}=0.6148\end{array}$ & $\begin{array}{l}\mathrm{y}=0.0011 \mathrm{x}+0.0668 \\
R^{2}=0.9964 \\
\mathrm{y}=0.00072 \mathrm{x}+0.0454 \\
R^{2}=0.9979\end{array}$ \\
\hline
\end{tabular}


405 Table2 Comparison of experimental values and theoretical values of adsorption of OA

406 and DTX1 toxins by HP20 resin simulated by the Pseudo-secondary kinetics equation.

\begin{tabular}{|c|c|c|c|c|c|}
\hline $\begin{array}{l}\text { Salinity of } \\
\text { seawater }\end{array}$ & Toxins & $\begin{array}{l}\text { Pseudo-secondary } \\
\text { kinetics equation }\end{array}$ & $\boldsymbol{h}$ & $\mathbf{Q}_{\mathrm{e}}, \mathbf{c a l}$ & $\mathbf{Q}_{\mathrm{e}}, \exp$ \\
\hline \multirow{2}{*}{$\begin{array}{l}\text { High salinity } \\
\qquad(27 \% \text { ) }\end{array}$} & $\mathrm{OA}$ & $y=0.00091 x+0.1153$ & 8.67 & 1100 & 901 \\
\hline & DTX1 & $y=0.00062 x+0.0816$ & 12.25 & 1610 & 1310 \\
\hline \multirow{2}{*}{$\begin{array}{l}\text { Medium } \\
\text { salinity } \\
(13.5 \% \text { ) }\end{array}$} & $\mathrm{OA}$ & $y=0.00098 x+0.0534$ & 18.73 & 1020 & 900 \\
\hline & DTX1 & $y=0.00069 x+0.0374$ & 26.74 & 1450 & 1290 \\
\hline \multirow{2}{*}{$\begin{array}{l}\text { Low salinity } \\
\qquad(9 \%)\end{array}$} & $\mathrm{OA}$ & $y=0.0011 x+0.0668$ & & 909 & 868 \\
\hline & DTX1 & $y=0.00072 x+0.0454$ & 22.03 & 1390 & 1280 \\
\hline
\end{tabular}

407 Note: $h(=1 / \mathrm{a})$ means the initial sorption rate $(\mathrm{ng} /(\mathrm{g} \cdot \mathrm{min}))$; $\mathrm{Q}_{\mathrm{e}}, \mathrm{cal}(=1 / \mathrm{b})$ means the

408 theoretical values were calculated according to the Pseudo-secondary kinetics

409 equations; $Q_{e}$,exp means the actual values were tested in the adsorption experiments.

410 
411 Table3 Specific surface areas and average pore volumes of HP20 resins before and

412 after adsorption for OA and DTX1 toxins in seawaters of different salinity.

\begin{tabular}{|c|c|c|c|c|}
\hline $\begin{array}{l}\text { Salinity of } \\
\text { seawaters }\end{array}$ & $\begin{array}{l}\text { Characteristic } \\
\text { index }\end{array}$ & $\begin{array}{l}\text { Before } \\
\text { adsorption for } \\
\text { toxins }\end{array}$ & $\begin{array}{l}\text { After } \\
\text { adsorption for } \\
\text { toxins }\end{array}$ & $\begin{array}{l}\text { Changing } \\
\text { ratio }(\%)\end{array}$ \\
\hline \multirow{2}{*}{$\begin{array}{l}\text { High } \\
\text { salinity } \\
(27 \% \text { o })\end{array}$} & $\begin{array}{l}\text { Specific surface } \\
\text { area }\left(\mathrm{m}^{2} / \mathrm{g}\right)\end{array}$ & 654.7 & 539.3 & -17.6 \\
\hline & $\begin{array}{l}\text { Average pore } \\
\text { volume }\left(\mathrm{cm}^{3} / \mathrm{g}\right)\end{array}$ & 1.30 & 1.18 & -9.2 \\
\hline \multirow{2}{*}{$\begin{array}{l}\text { Medium } \\
\text { salinity } \\
(13.5 \%)\end{array}$} & $\begin{array}{l}\text { Specific surface } \\
\text { area }\left(\mathrm{m}^{2} / \mathrm{g}\right)\end{array}$ & 558.3 & 546.0 & -2.2 \\
\hline & $\begin{array}{l}\text { Average pore } \\
\text { volume }\left(\mathrm{cm}^{3} / \mathrm{g}\right)\end{array}$ & 1.01 & 11 & +16.8 \\
\hline \multirow{2}{*}{$\begin{array}{l}\text { Low salinity } \\
(9 \% \text { ) }\end{array}$} & $\begin{array}{l}\text { Specific surface } \\
\text { area }\left(\mathrm{m}^{2} / \mathrm{g}\right)\end{array}$ & 604.5 & 552.3 & -8.6 \\
\hline & $\begin{array}{l}\text { Average pore } \\
\text { volume }\left(\mathrm{cm}^{3} / \mathrm{g}\right)\end{array}$ & 1.11 & 0.97 & -12.6 \\
\hline
\end{tabular}

Note: specific surface area was calculated by the BET model; average pore volume

414 (pore size $1.7-300 \mathrm{~nm}$ ) was calculated by the BJH model. 
415

416

417

418

419

420

421

422

423

424

425

426

427

428

429

430

431

432

\section{Legends of figures}

Fig.1. Chemical structures of OA and its analogue DTX1.

Fig.2. LC-MS/MS chromatograms of OA and DTX1 in one sample collected from the artificial seawater at low salinity after 30-min exposure in adsorption experiment. Three different transitions of parent ions $\mathrm{m} / \mathrm{z} 827.5$ and 841.5 were used to qualify OA and DTX1, respectively. The concentrations of OA and DTX1 in this sample were tested as 1.85 and $2.77 \mathrm{ng} / \mathrm{mL}$, respectively.

Fig.3. Dynamic adsorption curves of OA (a) and DTX1 (b) toxins by HP20 resin in seawaters with different salinity.

Fig.4. Average linear adsorption rates of OA (a) and DTX1 (b) toxins by HP20 resin in seawaters with different salinity calculated in different time period.

Fig.5. Accumulative pore volumes for different interval pore size of HP20 resin before and after adsorption for OA and DTX1 toxins in seawaters with different salinity.

Fig.6. Scanning electron microscopes (SEM) of HP20 resin before and after adsorption under different salinity conditions. SEM of high salinity blank (a) and high salinity (b), medium salinity blank (c) and medium salinity (d), low salinity blank (e) and low salinity (f) are compared separately. 


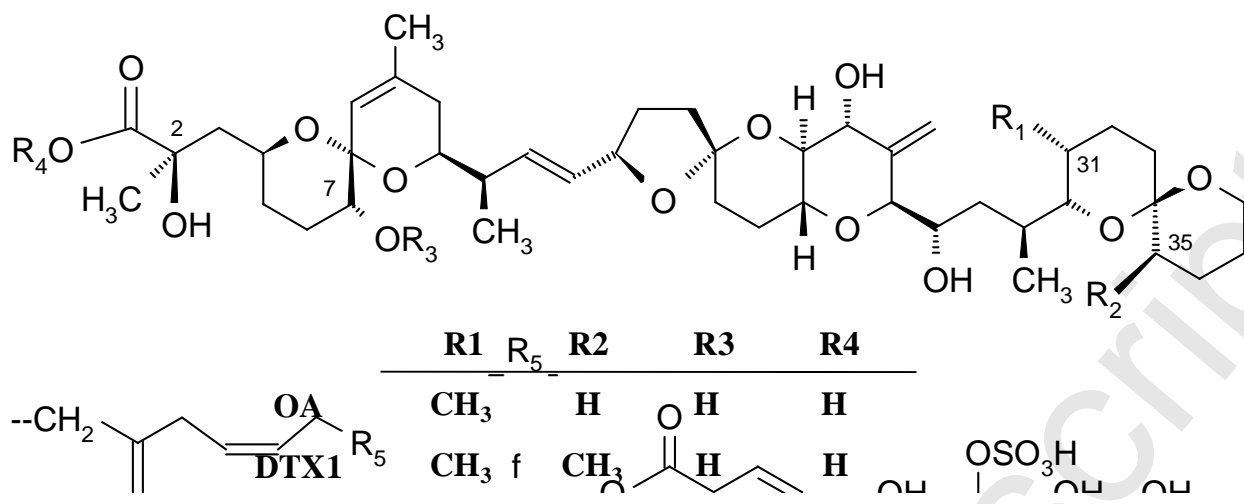

Fig. 1 


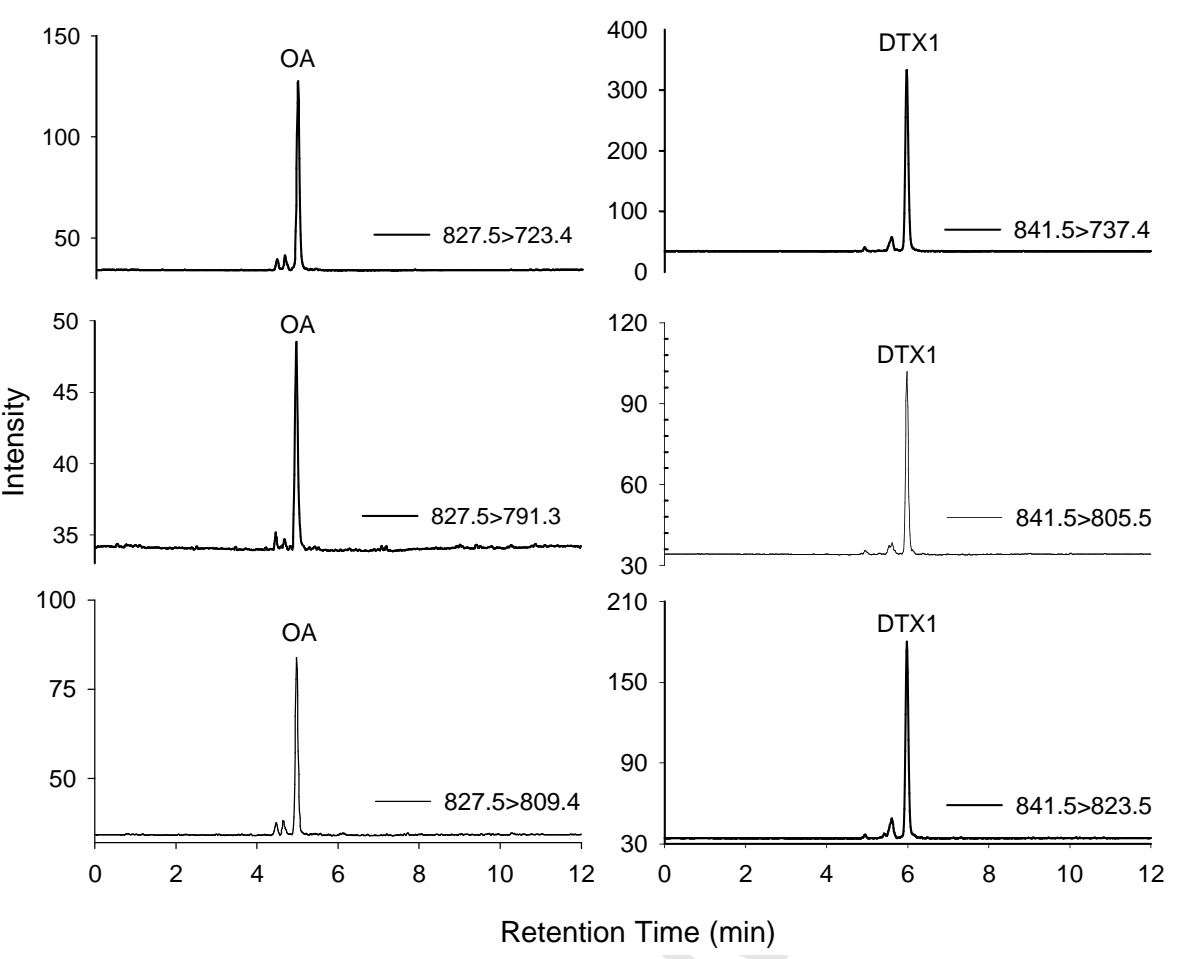

Fig.2 

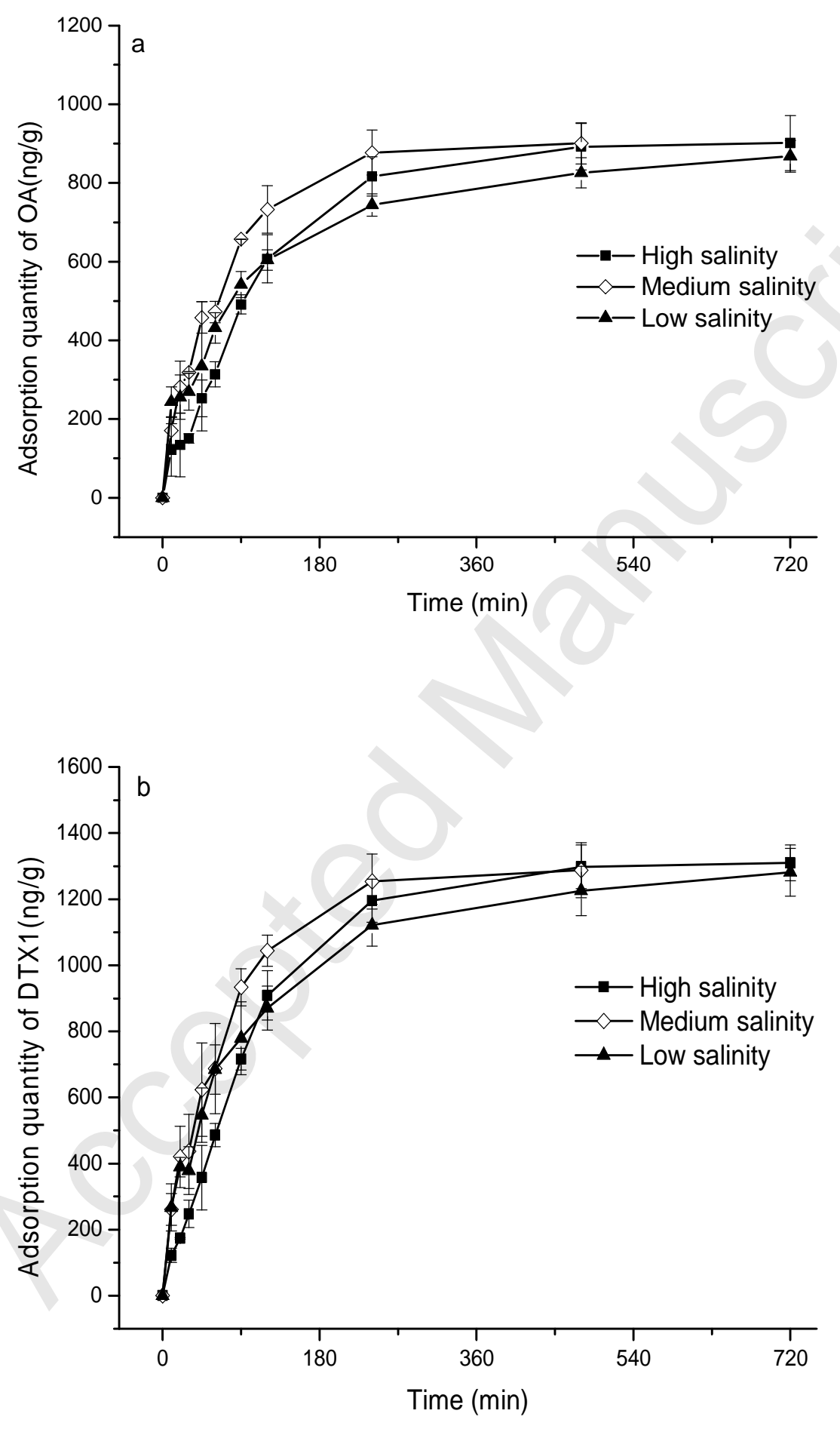

Fig. 3 

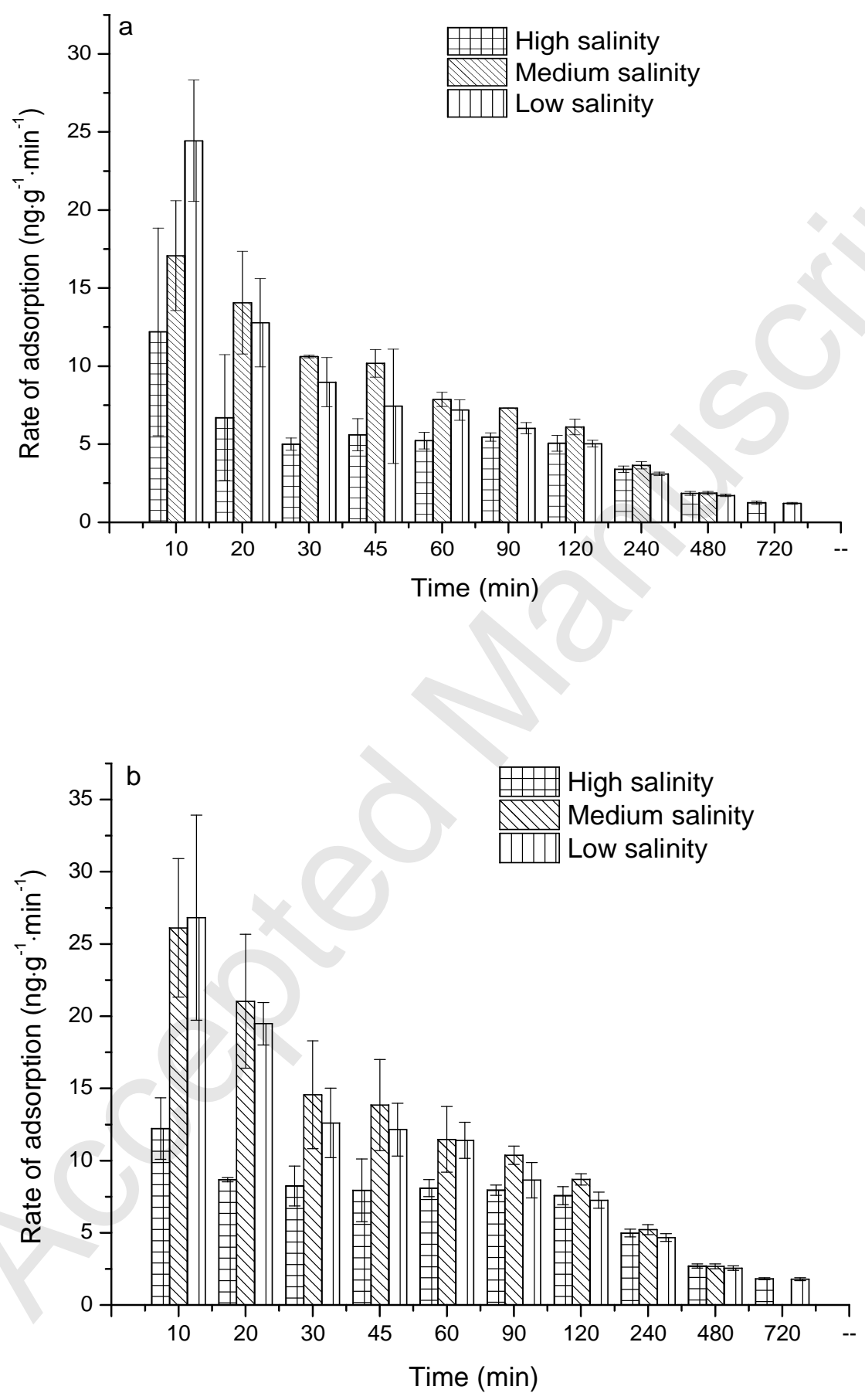

Fig. 4 


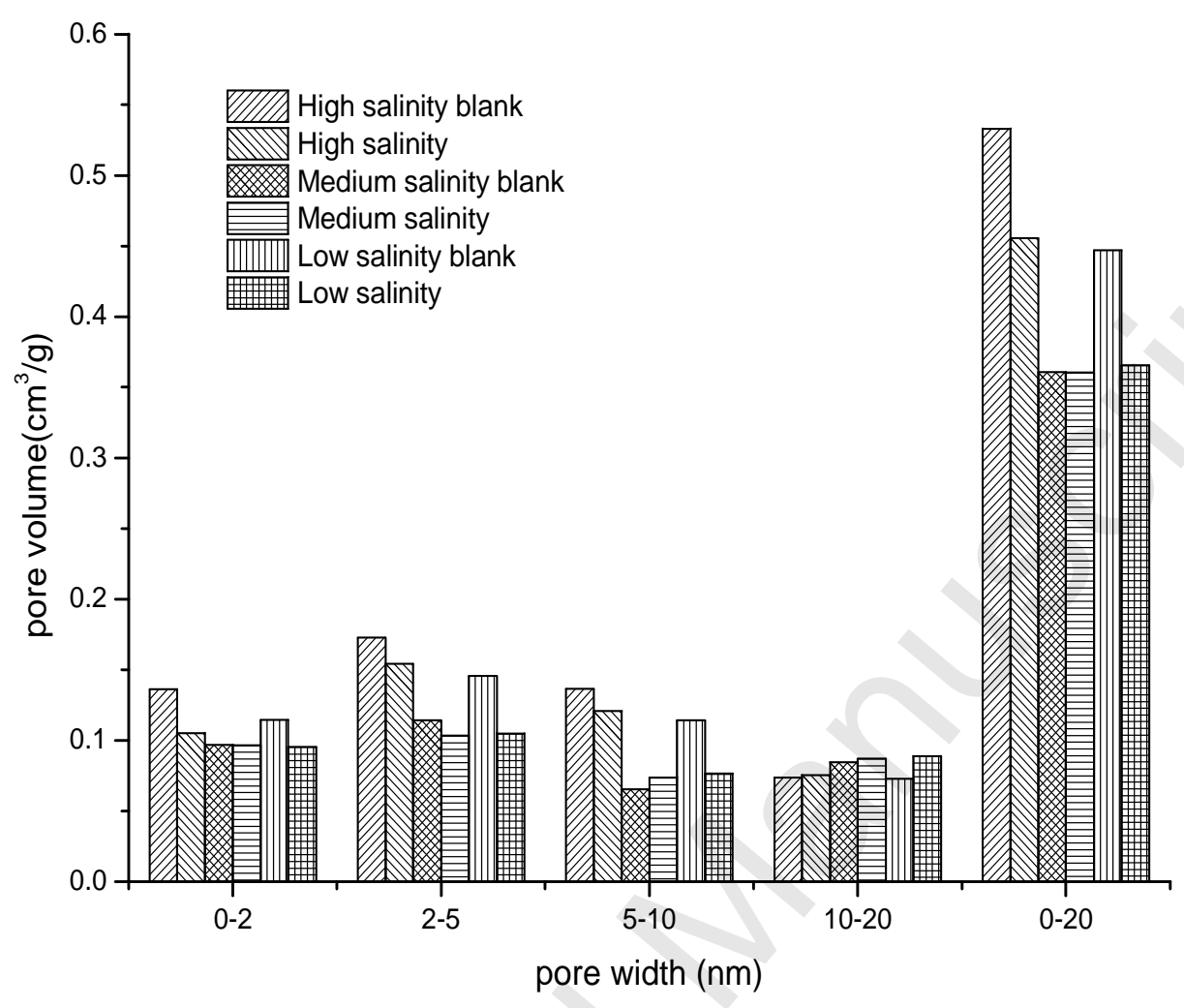

Fig. 5 

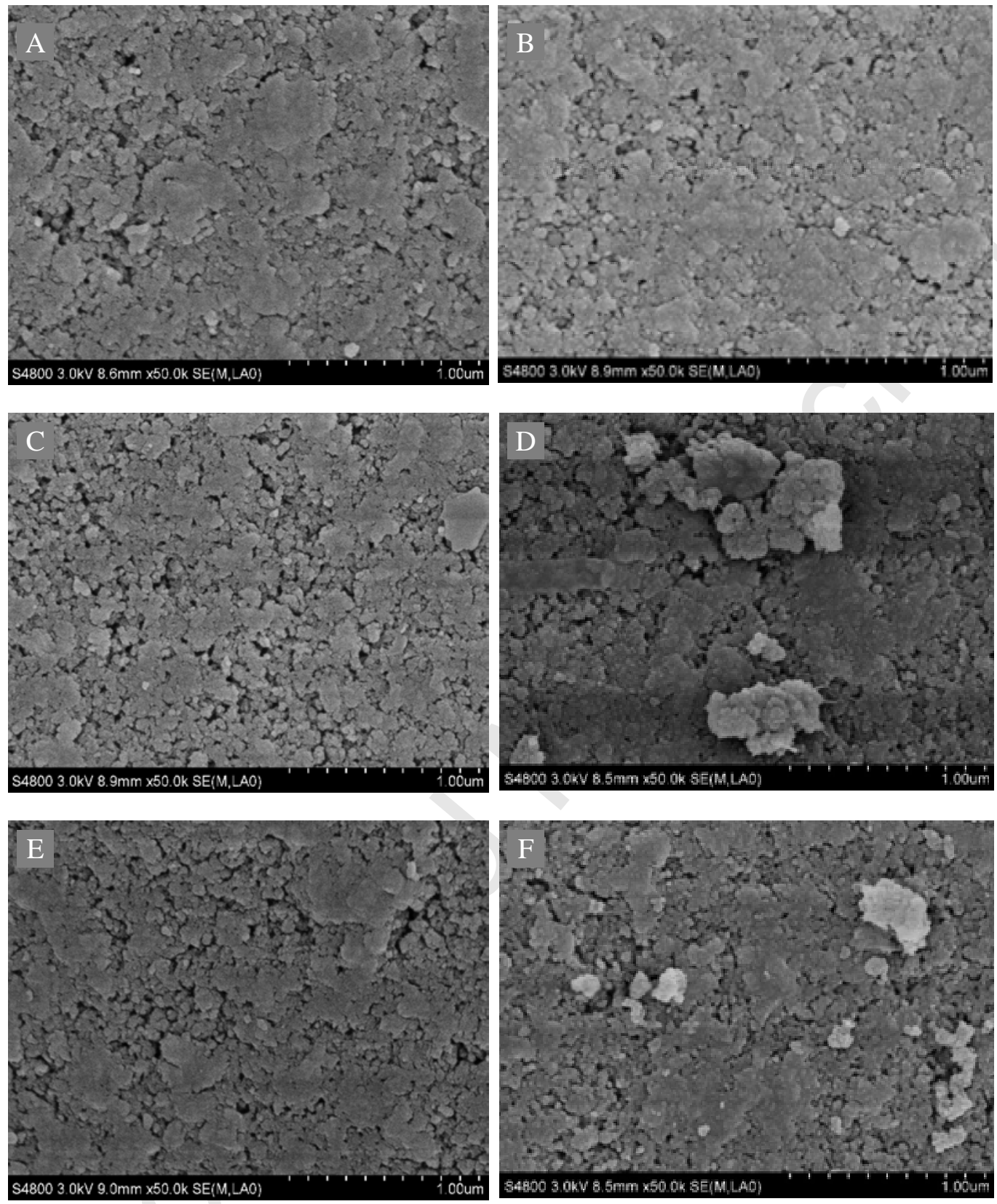

Fig. 6 